\title{
Chemical constituents of the ethyl acetate extract from the leaf of mugwort (Artemisia vulgaris L.)
}

\author{
Truong Van Nguyen Thien ${ }^{1}{ }^{*}$, Thien Tai Phan ${ }^{1}$, Tung Thanh Phan ${ }^{1}$, Lien Kim Thi Tran ${ }^{1}$, Nhu Tiet Thi Tran ${ }^{1}$, \\ Phu Hoang Dang ${ }^{1}$, Linh Phi Nguyen ${ }^{2}$, Quang That Ton ${ }^{1}$
}

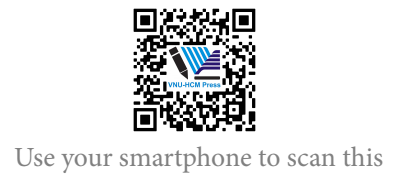

QR code and download this article

${ }^{1}$ Faculty of Chemistry, University of Science, VNU-HCM

${ }^{2}$ Central Laboratory for Analysis, University of Science, VNU-HCM

\section{Correspondence}

Truong Van Nguyen Thien, Faculty of Chemistry, University of Science, VNU-HCM

Email:ngttvan@hcmus.edu.vn

History

- Received: 27-12-2018

- Accepted: 22-3-2019

- Published: 30-11-2019

DOI : 10.32508/stdj.v22i4.1744

\section{Check for updates}

\section{Copyright}

(c) VNU-HCM Press. This is an openaccess article distributed under the terms of the Creative Commons Attribution 4.0 International license.

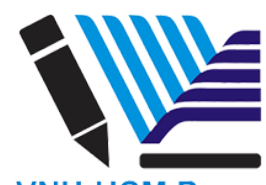

VNU-HCM Press

\begin{abstract}
Introduction: Mugwort (Artemisia vulgaris L.) is a familiar herbal medicine and also a daily vegetable. It is one of the ingredients in the famous remedy "Cao ích mẫu" specializing in menstrual disorders or the omelet with mugwort that helps save blood flow to the brain to treat headaches. In both traditional medicine and the new drugs, diseases are usually treated by mugwort as diabetes, epilepsy combination for psychoneurosis, depression, irritability, insomnia, anxiety, and stress. To demonstrate the medicinal uses, the chemical constituents of this herbal were continually studied. Methods: The leaves of mugwort were collected in Ba Ria Vung Tau province, Vietnam. The plant was identified by the late pharmacist and botanist Binh Duc Phan. A voucher specimen (AV001) was deposited in the herbarium of the Department of Organic Chemistry, VNUHCM-University of Science. Dried leaf powder of A. vulgaris (11 kg) was extracted with methanol and evaporated under reduced pressure to give a methanol extract (910 g), which was dissolved in methanol-water (1:9) and then successively partitioned with petroleum ether, chloroform, and ethyl acetate. From the previously researched ethyl acetate fraction, nine compounds were isolated: six known phenolic compounds (luteolin, 6-methoxyluteolin, eupatilin, o-coumaric acid, vanillic acid, and protocatechuic acid), sinapyl alcohol diisovalerate, vulgarin, and one new compound (artanoic acid). Results: In this research, ethyl acetate fraction was also studied. From subfraction EA4, six compounds were isolated by three skeletons: phenolic compounds (5,4' -dihydroxyflavone and 4-hydroxyphenyl acetate), phenyl propanoid (methyl 2-O- $\beta$-D-glucopyranosylcoumarate and 2-O- $\beta$-D-glucopyranosylcoumaric acid) and uracil (5-methyluracil and uridine). The structure of the isolated compounds was determined to base on 1D, 2D NMR spectra, HR-ESI-MS, and comparison with published data. Conclusion: Particularly, four compounds (methyl 2-O- $\beta$-D-glucopyranosylcoumarate, $2-\mathrm{O}-\beta$-D-glucopyranosylcoumaric acid, 5-methyluracil, and uridine) were known for the first time from this species.

Key words: mugwort, Artemisia vulgaris L., flavone, coumarin, and uracil
\end{abstract}

\section{INTRODUCTION}

Artemisia vulgaris L., a familiar herbal species in Viet $\mathrm{Nam}$, is used in both traditional medicine and new drugs. Diseases are usually treated by mugwort as diabetes, epilepsy combination for psychoneurosis, depression, irritability, insomnia, anxiety, and stress ${ }^{1}$. The primary responsibility for these activities are constituents, such as flavonoids, coumarins, sesquiterpene lactones, volatile oils, inulin, and traces of alkaloids $^{2}$. In the previous research of my group, three flavonoids (luteolin, 6-methoxyluteolin, and eupatilin), four phenolic compounds (o-coumaric acid, vanillic acid, protocatechuic acid, and sinapyl alcohol diisovalerate), and two sesquiterpene lactones (vulgarin and artanoic acid) are isolated from the ethyl acetate fraction ${ }^{3}$.

In this study, the ethyl acetate fraction is continuously researched and six compounds are isolated, in- cluding methyl 2-O- $\beta$-D-glucopyranosylcoumarate (1), 2-O- $\beta$-D-glucopyranosylcoumaric acid (2), 5methyluracil (3), uridine (4), 5,4'-dihydroxyflavone (5), and 4-hydroxyphenyl acetate (6).

\section{METHOD}

\section{General experimental procedures}

The NMR spectra were acquired on a Bruker Avance III $500 \mathrm{MHz}$ spectrometer with tetramethylsilane (TMS) as an internal standard, with chemical shifts expressed in $d(\mathrm{ppm})$ values. The HR-ESI-MS were determined with a MicrOTOF QII mass spectrometer (Bruker Daltonics). Analytical and preparative thinlayer chromatography (TLC) were performed on precoated Merck Kieselgel $60 \mathrm{~F}_{254}$ or RP-18 $\mathrm{F}_{254}$ plates ( $0.25 \mathrm{~mm}$ or $0.5 \mathrm{~mm}$ thickness). 


\section{Plant material}

The leaves of Artemisia vulgaris L. were collected at Lang Dai, Dat Do, Ba Ria - Vung Tau province, Vietnam on May 2011. The plant was identified by the late pharmacist and botanist Binh Duc Phan. A voucher specimen (AV001) was deposited in the herbarium of the Department of Organic Chemistry, VNUHCMUniversity of Science.

\section{Extraction and isolation}

From the ethyl acetate fraction in the previous research $^{3}$, fraction EA4 (6.14 g) was subjected to silica gel column chromatography eluting with petroleum ether -ethyl acetate, followed by ethyl acetate methanol with increasing polarity to yield six fractions (EA4.1 - 6). Fraction EA4.3 (300.6 mg) was separated over a silica gel column eluted with chloroform-methanol (from 9.5:0.5 to 0:10), as well as preparative TLC, eluted with petroleum etheracetone (4:6) to afford $\mathbf{1}(6.0 \mathrm{mg}), \mathbf{2}(5.5 \mathrm{mg})$, and $\mathbf{6}$ $(8.2 \mathrm{mg})$. Fraction EA4.4 (207.5 mg) was subjected to Sephadex LH-20 column eluted with methanol, and further fractionated by silica gel column chromatography eluted with chloroform- ethyl acetate (from 9:1 to $3: 7)$ to obtain 3 (6.3 mg), 4 (4.0 mg), and 5 (4.5 mg).

\section{RESULTS AND DISCUSSION}

Six compounds $(\mathbf{1}-\mathbf{6})$ were isolated from the ethyl acetate fraction of the leaves of Artemisia vulgaris L.

Compound 1 was obtained as a white amorphous powder, and its molecular formula was determined as $\mathrm{C}_{16} \mathrm{H}_{20} \mathrm{O}_{8}$ by HR-ESI-MS analysis at $m / z 341.1161$ $[\mathrm{M}+\mathrm{H}]^{+}$. The ${ }^{1} \mathrm{H}-\mathrm{NMR}$ spectrum of $\mathbf{1}$ showed four signals of four aromatic protons at $\delta_{H} 7.02(1 \mathrm{H}, d d$, 7.5, $7.5 \mathrm{~Hz}, \mathrm{H}-5), \delta_{H} 7.19(1 \mathrm{H}, d, 8.5 \mathrm{~Hz}, \mathrm{H}-3), \delta_{H}$ $7.37(1 \mathrm{H}, d d d, 8.5,7.5,1.5 \mathrm{~Hz}, \mathrm{H}-4), \delta_{H} 7.71(1 \mathrm{H}, d d$, $7.5,1.5 \mathrm{~Hz}, \mathrm{H}-6)$. Furthermore, the ${ }^{13} \mathrm{C}-\mathrm{NMR}$ and HSQC spectra showed aromatic carbon signals at $\delta_{C}$ 115.5 (C-3), 122.3 (C-5), 128.7 (C-6), 132.1 (C-4), and two signals of quartet carbon at $\delta_{C} 123.4(\mathrm{C}-1), \delta_{C}$ 156.1 (C-2). It demonstrated that 1 had a 1,2-di substituted benzene. There were two signals of two olefin protons, (E) configuration, at $\delta_{H} 7.95(1 \mathrm{H}, d, 16.0 \mathrm{~Hz}$, $\mathrm{H}-7)$, and $\delta_{H} 6.64(1 \mathrm{H}, d, 16.5 \mathrm{~Hz}, \mathrm{H}-8)$ with carbon signals at $\delta_{C} 139.8(\mathrm{C}-7), \delta_{C} 118.7(\mathrm{C}-8)$; and a carboxyl group at $\delta_{C} 167.3$ (C-9). HMBC correlations between H-7/C-2, C-8, C-9; H-8/C-9 showed that 1 had the 2-h ydroxycinnamoyl skeleton. The signals of a methoxy group at $\delta_{H} 3.70(3 \mathrm{H}, s, \mathrm{H}-10)$ and $\delta_{C} 51.7$ (C-10), correlated with C-9 in the HMBC spectrum (Figure 1). Therefore, the methoxy group linked to the carboxyl group of the cinnamoyl skeleton.

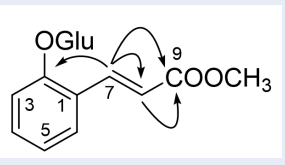

Figure 1: Significant HMBC $(\rightarrow)$ correlations of 2hydroxycinnamoyl skeleton.

${ }^{1} \mathrm{H}-\mathrm{NMR}$ and ${ }^{13} \mathrm{C}-\mathrm{NMR}$ spectra showed an anomer proton at $\delta_{H} 5.00\left(1 \mathrm{H}, d, 8.5 \mathrm{~Hz}, \mathrm{H}-1^{\prime}\right)$ and $\delta_{C} 100.4$ $\left(\mathrm{C}-1^{\prime}\right)$. The HMBC correlation between $\mathrm{H}-1^{\prime} / \mathrm{C}-2, \mathrm{C}-$ $3^{\prime}$ showed that the sugar moiety linked to cinnamoyl skeleton at C-2.

The above data compared with the published one indicated that $\mathbf{1}$ was methyl $2-\mathrm{O}-\beta-\mathrm{D}$ glucopyranosylcoumarate ${ }^{4}$.

Compound 2 was obtained as a white amorphous powder, and its molecular formula was determined as $\mathrm{C}_{15} \mathrm{H}_{18} \mathrm{O}_{8}$ by HR-ESI-MS analysis at $m / z 326.1033$ $[\mathrm{M}]^{+}$, calcd 326.1002. The ${ }^{1} \mathrm{H}-\mathrm{NMR},{ }^{13} \mathrm{C}-\mathrm{NMR}$ spectra of $\mathbf{2}$ were similar to those of compound $\mathbf{1}$. However, the lack of the methoxy group in compound 2 showed that it was a carboxylic acid. The comparison of the above data with the one in the literature ${ }^{5}$ assigned 2 as $O$-coumarico glucosidase acid.

Compound 3 was obtained as a white amorphous powder and its molecular formula was determined as $\mathrm{C}_{5} \mathrm{H}_{6} \mathrm{~N}_{2} \mathrm{O}_{2}$ by HR-ESI-MS analysis at $m / z 127.0451$ $[\mathrm{M}+\mathrm{H}]^{+}$. The ${ }^{1} \mathrm{H}-\mathrm{NMR}$ spectrum displayed four signals including two amide protons at $\delta_{H} 10.56(\mathrm{br})$, and $\delta_{H} 10.97(b r)$, a methyl group at $\delta_{H} 1.71(3 \mathrm{H}, d$, $1.0 \mathrm{~Hz}, \mathrm{H}-7)$, and an olefin proton signal at $7.23(1 \mathrm{H}$, s). The ${ }^{13} \mathrm{C}$-NMR and HSQC spectra showed two signals of two carbonyl carbons at $\delta_{C} 165.2(\mathrm{C}-2)$ and $151.7(\mathrm{C}-4)$, two olefin signals at $\delta_{C} 108.2(\mathrm{C}-5)$ and $138.2(\mathrm{C}-6)$ and a methyl group at $\delta_{C} 12.2(\mathrm{C}-7)$. The above information showed an uracil skeleton in compound 3. The HMBC correlations between H-7/C-5, C- 6 confirmed the position of the methyl group on the C-5 of the uracil skeleton (Figure 2).

Based on the above discussions and the comparison with the published ones ${ }^{5}$, the structure of 3 was 5 methyluracil.

Compound 4 was obtained as a white amorphous powder and its molecular formula was determined as $\mathrm{C}_{9} \mathrm{H}_{12} \mathrm{~N}_{2} \mathrm{O}_{6}$ by HR-ESI-MS analysis at $m / z 267.0628$ $[\mathrm{M}+\mathrm{Na}]^{+}$and $m / z 245.0825[\mathrm{M}+\mathrm{H}]^{+} \cdot{ }^{1} \mathrm{H}-\mathrm{NMR},{ }^{13} \mathrm{C}$ -NMR, HSQC spectra showed that compound 4 had the uracil skeleton as in compound 3. The ${ }^{1} \mathrm{H}-\mathrm{NMR}$ spectrum showed an amide proton at $\delta_{H} 11.29(\mathrm{br})$, two olefin protons with the $(\mathrm{Z})$ configuration at $\delta_{H}$ $7.88(1 \mathrm{H}, d, 8.0 \mathrm{~Hz}, \mathrm{H}-6), 5.64(1 \mathrm{H}, d, 8.0 \mathrm{~Hz}, \mathrm{H}-5)$. 


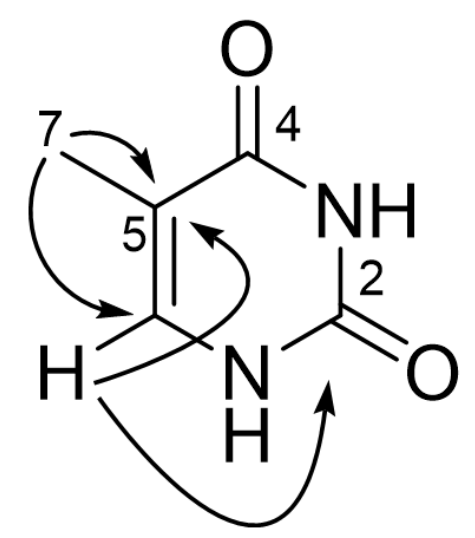

Figure 2: Significant HMBC $(\rightarrow)$ correlations of uracil skeleton.
The ${ }^{13} \mathrm{C}$-NMR spectrum showed two olefin carbons at $\delta_{C} 102.2(\mathrm{C}-5)$ and $\delta_{C} 141.2(\mathrm{C}-6)$; two carbonyl groups at $\delta_{C} 163.6(\mathrm{C}-2)$ and $\delta_{C} 151.2(\mathrm{C}-4)$.

In addition, there was an anomer proton at $\delta_{H} 5.77$ $\left(1 \mathrm{H}, d, 5.5 \mathrm{~Hz}, \mathrm{H}-1^{\prime}\right)$ and five oxymethine proton of a sugar moiety at $\delta_{H} 3.53-5.36$ in the ${ }^{1} \mathrm{H}-\mathrm{NMR}$ spectrum. The ${ }^{13} \mathrm{C}$-NMR spectrum showed an anomer carbon at $\delta_{C} 88.1\left(\mathrm{C}-1^{\prime}\right)$, and four oxynated carbons at $\delta_{C} 85.4\left(\mathrm{C}-4^{\prime}\right), 73.8\left(\mathrm{C}-2^{\prime}\right), 70.3\left(\mathrm{C}-3^{\prime}\right)$ and 61.2 $\left(\mathrm{C}-5^{\prime}\right)$. It demonstrated a sugar moiety in compound 4.

The HMBC correlations between proton $\mathrm{H}-6 / \mathrm{C}-2, \mathrm{C}-$ 4, C-5 and C- $1^{\prime}$, proton $\mathrm{H}-5 / \mathrm{C}-2, \mathrm{C}-6, \mathrm{C}-1^{\prime}$, and the anomer proton $\mathrm{H}-1^{\prime} / \mathrm{C}-2, \mathrm{C}-5, \mathrm{C}-6, \mathrm{C}-2^{\prime}, \mathrm{C}-3^{\prime}, \mathrm{C}-4^{\prime}$ showed that the sugar moiety linked to the first nitrogen of the uracil skeleton (Figure 3).

The above data compared with the published one indicated that 4 was uridine ${ }^{6}$.

Compound $\mathbf{5}$ was obtained as a yellow amorphous powder and its molecular formula was determined as $\mathrm{C}_{15} \mathrm{H}_{10} \mathrm{O}_{4}$ by HR-ESI-MS analysis at $\mathrm{m} / z 254.0593$ $[\mathrm{M}]^{+}$, calcd 254.0579. The ${ }^{1} \mathrm{H}-\mathrm{NMR}$ spectrum displayed two signals of four aromatic protons of a 1,4disubstituted benzene at $\delta_{H} 7.91(2 \mathrm{H}, d, J=8.5 \mathrm{~Hz}$, $\mathrm{H}-2^{\prime}$ and $\left.\mathrm{H}-6^{\prime}\right)$ and $6.91 \mathrm{~Hz}\left(2 \mathrm{H}, d, J=8.5 \mathrm{~Hz}, \mathrm{H}-3^{\prime}\right.$ and $\left.\mathrm{H}-5^{\prime}\right)$. Moreover, there were three signals of three aromatic protons of a 1,2,3-trisubstituted benzene at $\delta_{H} 7.32(1 \mathrm{H}, s, J=2.5 \mathrm{~Hz}, \mathrm{H}-8) ; 7.53(2 \mathrm{H}, d, J=7.5$ $\mathrm{Hz}, \mathrm{H}-6$ and H-7) and an olefin proton at $\delta_{H} 7.08(1 \mathrm{H}$, $s, J=2.5 \mathrm{~Hz}, \mathrm{H}-3)$. The ${ }^{13} \mathrm{C}-\mathrm{NMR}$ spectrum showed fifteen carbons: seven aromatic quaternary carbons $\left(\delta_{C} 182.9,167.4,162.4,158.3,149.8,120.7,109.9\right)$, eight aromatic methine carbons $\left(\delta_{C} 115.9\right.$ (C-3', C$\left.5^{\prime}\right), 132.7\left(\mathrm{C}-2^{\prime}, \mathrm{C}-6^{\prime}\right), 110.8,130.2,107.1$ and 102.5).

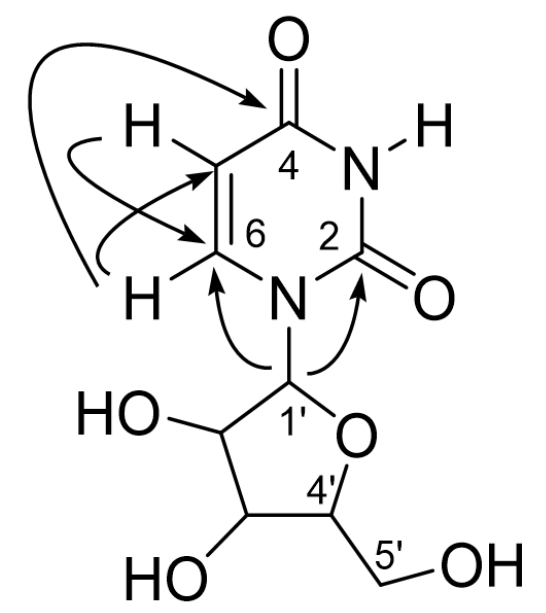

Figure 3: Significant HMBC $(\rightarrow)$ correlations of compound 4.

Based on the above discussions and the comparison with the published one ${ }^{7}$, the structure of $\mathbf{5}$ was $5,4^{\prime}$ -dihydroxyflavone.

Compound 6 was obtained as a white amorphous powder, and its molecular formula was determined as $\mathrm{C}_{8} \mathrm{H}_{8} \mathrm{O}_{3}$ by HR-ESI-MS analysis at $m / z 175.0377$ $[\mathrm{M}+\mathrm{Na}]^{+}$, calcd 175.0371. The ${ }^{1} \mathrm{H}-\mathrm{NMR}$ spectrum showed two signals of four aromatic protons of a 1,4disubstituted benzene at $\delta_{H} 7.44(2 \mathrm{H}, d, J=9.0 \mathrm{~Hz})$ and $6.74(2 \mathrm{H}, d, J=9.0 \mathrm{~Hz})$, one methyl group at $\delta_{H} 2.01(3 \mathrm{H}, s)$, and one hydroxyl at $\delta_{H} 8.93(1 \mathrm{H}$, $s)$. The ${ }^{13} \mathrm{C}$-NMR spectrum showed four signals of six aromatic carbons $\left(\delta_{C} 154.2,121.7,121.6,115.8\right)$, one methyl group $\left(\delta_{C} 24.0\right)$, and one carboxyl group $\left(\delta_{C}\right.$ 171.4). On the basis of the above discussions and the comparison with the published one ${ }^{8}$, the structure of 6 was 4-hydroxyphenyl acetate.

\section{CONCLUSION}

From the leaves of Artemisia vulgaris L. collected at $\mathrm{Ba}$ Ria - Vung Tau province, six compounds were isolated, including methyl 2-O- $\beta$-D-glucopyranosylcoumarate (1), 2-O- $\beta$-Dglucopyranosylcoumaric acid (2), 5-methyluracil (3), uridine (4), 5,4'-dihydroxyflavone (5), and 4-hydroxyphenyl acetate (6). Compounds 1, 2, 3, 4 were known for the first time from this species.

\section{LIST OF ABBREVIATIONS}

1D NMR: One-dimensional nuclear magnetic resonance;

2D NMR: Two-dimensional nuclear magnetic resonance; 
13 C-NMR: Carbon-13 nuclear magnetic resonance;

${ }^{1}$ H-NMR: Proton nuclear magnetic resonance;

HR-ESI-MS: High-resolution electrospray ionization mass;

TMS: Tetramethylsilane;

TLC: Thin-layer chromatography;

EA: Ethyl acetate;

HMBC: Heteronuclear Multiple Quantum Coherence.

\section{COMPETING INTERESTS}

The authors declare that they have no conflicts of interest.

\section{AUTHORS' CONTRIBUTIONS}

Truong Van Nguyen Thien, Thien Tai Phan, Tung Thanh Phan, Kim Lien Tran Thi, Nhu Tiet Thi Tran, and Phu Hoang Dang have contributed in conducting experiments, getting hold of data and writing the manuscript.

Linh Phi Nguyen, Quang Ton That have contributed significantly explanation of data and revising the manuscript.

\section{ACKNOWLEDGMENT}

This work was supported by Grant T2018-11 from VNUHCM - University of Science.

\section{REFERENCES}

1. Walter HL, Memory PF, Elvin L. Medical Botany, 2nd Ed. vol. 345 . New Jersey: John Wiley and Sons; 2003.

2. Bamoniri A, Mirjalili BBF, Mazoochi A, Batooli HJ. Chemical composition of Artemisia Vulgaris L. from Kashan area isolated by nano scale injection. Iranian Journal of Organic Chemistry. 2010;2:533-536.

3. Thien TVN, Tran LTK, Tran NTT, Duc TP, Do LTM, Tu DD, et al. A new eudesmane-type sesquiterpene from the leaves of Artemisia vulgaris. Chemistry of Natural Compounds. 2018;54:66-68.

4. Purohit MC, Rauat MSM, Pant G, Nautiyal AK, Sakakibara, Kaiya T. A methyl ester of melilotoside from the sapwood of Prunus cornuta. Phytochemistry. 1993;32:431-432.

5. Kan S, Chen G, Han C, Chen Z, Sibirium X. Chemical consituent from the roots of Xanthium sibirium. Natural Product Research: Formerly natural product letters. 2011;25:1243-1249.

6. Zhang X, Wang J, Xu YW. Systematic assignment of NMR spectra of 5-substituted-4-thiopyrimidine nucleosides. Magnetic Resonance in Chemistry. 2013;51:523-529.

7. Ibrahim AR, Abul-Hajj YJ. Aromatic Hydroxylation and Sulfation of 5-Hydroxyflavone by Streptomyces fulvissimus. Applied and Environmental Microbiology. 1989;55:3140-3142.

8. Cepanec I, Litvić M. Simple and efficient synthesis of arbutin. Arkivoc. 2008;p. 19-24. 